\section{Bilateral Circular Xanthelasma Palpebrarum}

Jungmin Kim, Yu Jin Kim, Hyoseob Lim, Se Il Lee

Department of Plastic and Reconstructive Surgery, Gachon University Gil Hospital, Incheon, Korea

\section{Correspondence: Yu Jin Kim}

Department of Plastic and Recontructive Surgery, Gachon University Gil Hospital, 21 Namdong-daero 774beon-gil, Namdong-gu, Incheon 405-760 Korea

Tel: +82-1577-2299, Fax: +82-32-461-2774

E-mail: pseugene@gilhospital.com

No potential conflict of interest relevant to this article was reported.

Received: 29 Mar 2012 • Revised: 16 May 2012 • Accepted: 30 May 2012 pISSN: 2234-6163 • elSSN: 2234-6171

http://dx.doi.org/10.5999/aps.2012.39.4.435 • Arch Plast Surg 2012;39:435-437

Copyright (c) 2012 The Korean Society of Plastic and Reconstructive Surgeons

This is an Open Access article distributed under the terms of the Creative Commons Attribution Non-Commercial License (http://creativecommons.org/licenses/by-nc/3.0/) which permits unrestricted non-commercial use, distribution, and reproduction in any medium, provided the original work is properly cited.

Xanthelasma palpebrarum is the most common cutaneous xanthoma. It is most often around the medial side of the eyelids, and typically presents in middleaged and older adults [1]. A case of bilateral extensive xanthelasma palpebrarum that involves the entire upper and lower eyelids, resembling a pair of circles, has not been reported.
A 53-year-old female visited our department complaining of bilateral circular yellowish skin lesions around the upper and lower eyelids (Fig. 1). The lesions started to appear one year prior to admission at the medial aspect of the upper and lower eyelids and spread to the lateral sides. The patient complained that she felt inconvenienced or that opening her eyelids felt somewhat heavy and worried about the cosmetic appearance. Based on the clinical manifestation alone, the diagnosis of xanthelasma palpebrarum could be made. The patient was otherwise healthy, and her medical history was noncontributory. She had no history of using medication for hyperlipidemia or cardiovascular disease. Her parents had no history of xanthelasma palpebrarum. She had seven siblings. No one in her family had used medication for cardiovascular diseases such as hypertension, hyperlipidemia, or diabetes. Among them, only one sister had experienced xanthelasma palpebrarum, which had been limited to the medial side of the upper eyelid, and she had been treated with laser ablation in a local dermatology clinic.

On physical examination, the yellowish flat lesions involved both the upper and lower eyelids, resembling a pair of circles. The lesions of the medial side of both of the upper eyelids were especially large and the other sides were linear and curved. The sizes (horizontal

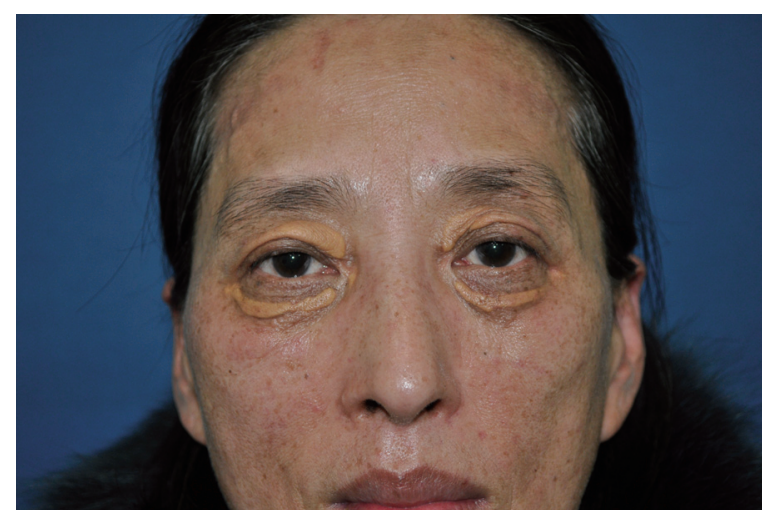

Fig. 1.

Preoperative view. A 53-year-old female presented bilateral circular yellowish skin lesions around the upper and lower eyelids.

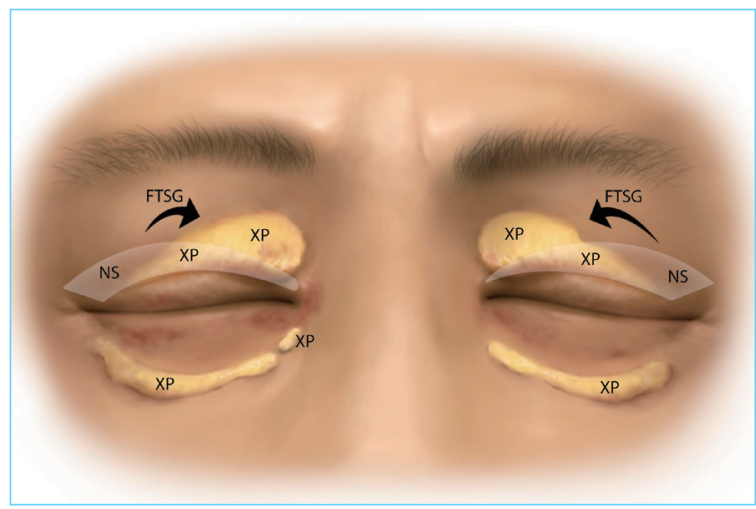

Fig. 2.

Schematic picture of the operation. The lesion of the lower eyelids were excised marginally and directly closed. Blepharoplasty with excision of xanthelasma palpebrarum was performed on the upper eyelids. The raw surface of the medial side was covered with the normal skin excised from the lateral side through the blepharoplasty incision. XP, xanthelasma palpebrarum; NS, normal skin; FISG, full-thickness skin graft. 
length $\mathrm{x}$ largest longitudinal height) were: $35 \times 8 \mathrm{~mm}$ (right upper eyelid); $40 \times 9 \mathrm{~mm}$ (left upper eyelid); $30 \times 5 \mathrm{~mm}$ (right lower eyelid); and $50 \times 5 \mathrm{~mm}$ (left lower eyelid). There was no limitation of the extraocular muscle movement. Laboratory tests were evaluated before surgery. The total cholesterol, highdensity lipoprotein cholesterol, and triglyceride levels were $255 \mathrm{mg} / \mathrm{dL}$ (range, 120 to $220 \mathrm{mg} / \mathrm{dL}$ ), $52 \mathrm{mg} /$ $\mathrm{dL}$ (range, 35 to $88 \mathrm{mg} / \mathrm{dL}$ ), and $109 \mathrm{mg} / \mathrm{dL}$ (<200 $\mathrm{mg} / \mathrm{dL}$ ). Respectively, the total cholesterol level was in the higher than normal range.

Two separate operations were performed. The lesions of the lower eyelids were excised first. The incision was performed along the margins of the lesions and skin, and strips of orbicularis oculi muscle were excised. Skin closure was performed with 6-0 black silk sutures. Four weeks later, the second operation, consisting of an upper blepharoplasty and a fullthickness skin graft, was performed. Excision was performed on the lateral side of the upper eyelid including the redundant normal skin. Marginal excision was performed on the medial side around the lesions because the lesions were larger than the redundant normal skin. Therefore, a full-thickness skin graft from the excised excessive normal skin was applied on the medial side, and the primary closure was performed on the lateral side (Fig. 2).

On follow-up 2 months after the second operation, she had no demonstrable clinical problems and was satisfied with the results (Fig. 3).

The histopathology showed flat $\neg$ tened epidermis with mild hyperkeratosis. The dermis was diffusely infiltrated by large, foamy, and lipid-laden histiocytes called "xanthoma cells" (Fig. 4).

Jee et al. [1] reported that xanthelasma palpebrarum is most commonly found symmetrically in the upper eyelid (70.3\%), with an almost oval appearance and smaller than $1 \mathrm{~cm}$ in diameter. Hyperlipidemia is reported to occur in $42.4 \%$ of the patients with xanthelasma. The prevalence is about $0.3 \%$ to $1.1 \%$. Xanthelasma palpebrarum is more common in females, occurring 1.8 times more than in males, and occurs more frequently with age, especially in patients over fifty years old. The typical clinical appearance is asymmetric, orange- or yellowish-colored papule in the medial side of the upper eyelid and is asymptomatic.

Postoperative 2-month view. The scars, which were made from marginal excision and direct closure, are shown in the lower eyelids.

The sites of the full-thickness skin graft in the upper eyelids are shown with a good matching skin color and texture. There is no sign or symptom of ectropion.
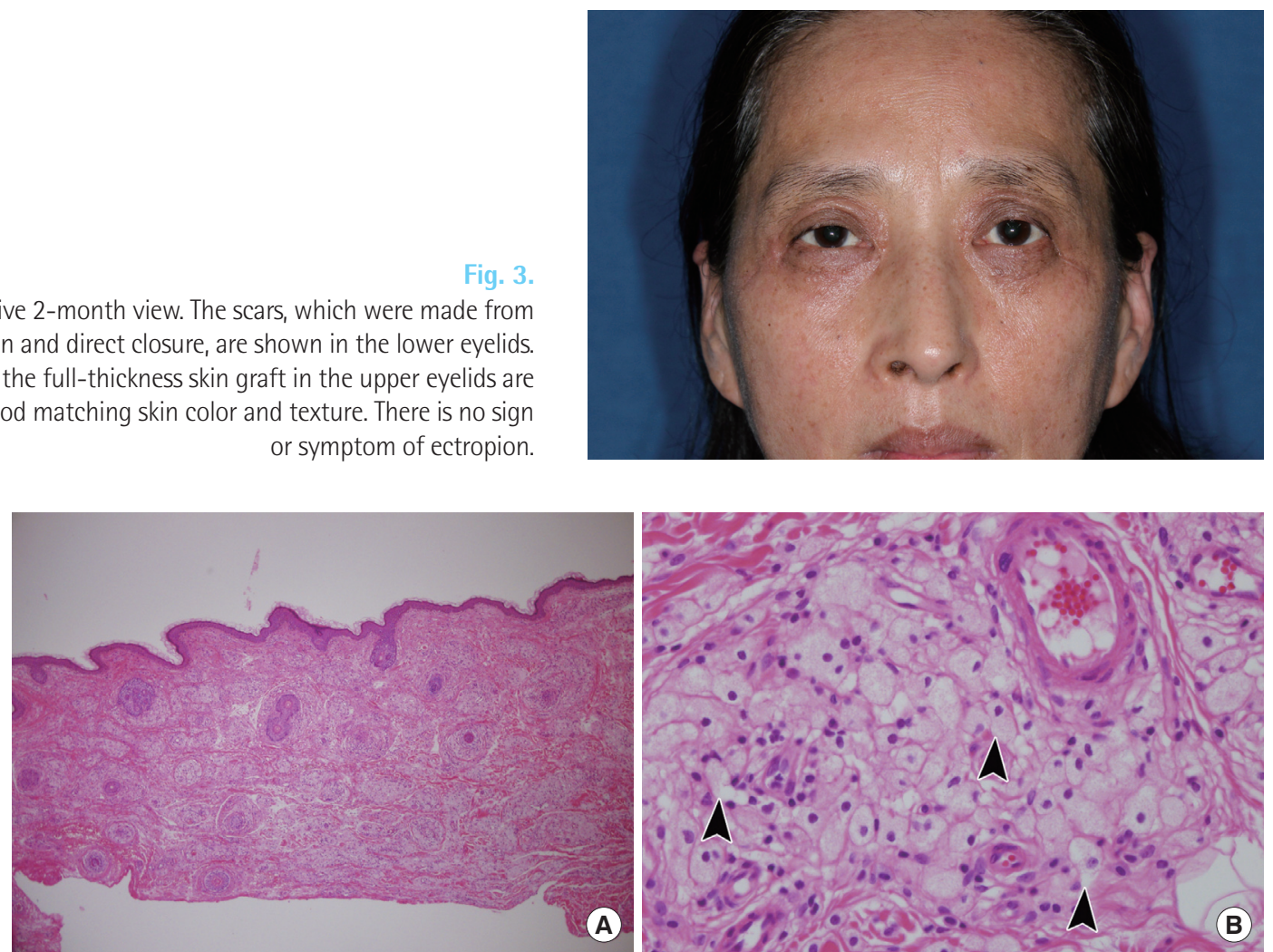

Fig. 4 .

Histopathologic findings of the left upper eyelid lesion. (A) Pale areas containing foamy cells are dispersed throughout the dermis $\left(H \& E_{1} \times 40\right)$ (B) Xanthoma cells. These foamy histiocytes are polygonal or rounded with a distinct cell membrane. Their nuclei were small and eccentric and their cytoplasms are stuffed with lipid vacuoles (black arrowheads) $\left(H \& E_{1} \times 400\right)$ 
Some cases of extensive bilateral xanthelasma palpebrarum have been reported. In those cases, similar to our case, soft and yellow plaques involved all four eyelids. The histopathologic findings were described well, but the treatment methods were not mentioned or almost all were laser ablations $[2,3]$.

Rohrich et al. [4] suggested current management principles for xanthelasma palpebrarum. An algorithmic approach to the treatment of xanthelasma includes surgical excision, laser ablation, and trichloroacetic acid. If the xanthelasma lesion is smaller than $3 \mathrm{~mm}$ and within the range of blepharoplasty incision, blepharoplasty or modified blepharoplasty can be performed. If the xanthelasma lesion is smaller than $3 \mathrm{~mm}$ and outside the range of blepharoplasty incision, direct elliptical incision, traditional trichloroacetic acid peel, or laser ablation can be used. If the xanthelasma lesion is larger than $3 \mathrm{~mm}$, serial excision or laser ablation can be selected. If the xanthelasma lesion is hard, uncapping removal and closure can be performed when the lesion is outside the blepharoplasty incision. In the present case, a full-thickness skin graft was chosen instead of staged excision.

Our case illustrates a rare case of xanthelasma palpebrarum that was bilateral, extensive or wide, circular, and had rapidly developed one year prior to treatment. There was no strong familial history of xanthelasma palpebrarum or hyperlipidemia. We removed the lesion only using surgical methods. Although the size of the lesion was larger than $4 \mathrm{~mm}$, we performed a full-thickness skin graft with the excised normal skin, instead of serial excision, with the lesion on the same side. This resulted in a good matching skin color and texture, and no donor-site scarring.

\section{References}

1. Jee MS, Chang SE, Choi JH, et al. Clinicopathologic study of 37 cases of xanthelasma palpebrarum; clinical significance of xanthelasma palpebrarum in hyperlipidemiae and cardiovascular diseases. Korean J Dermatol 2003;41:333-7.

2. Depot MJ, Jakobiec FA, Dodick JM, et al. Bilateral and extensive xanthelasma palpebrarum in a young man. Ophthalmology 1984;91:522-7.

3. Yoon SY, Cho JH, Bae EY, et al. A case of bilateral extensive xanthelasma. Korean J Dermatol 2005;43:675-7.

4. Rohrich RJ, Janis JE, Pownell PH. Xanthelasma palpebrarum: a review and current management principles.

Plast Reconstr Surg 2002;110:1310-4. 